ARTICLE

https://doi.org/10.1038/s41467-019-09986-1

\title{
Differences in $S / G$ ratio in natural poplar variants do not predict catalytic depolymerization monomer yields
}

Eric M. Anderson ${ }^{1,5}$, Michael L. Stone ${ }^{1,5}$, Rui Katahira2 ${ }^{2}$, Michelle Reed ${ }^{2}$, Wellington Muchero ${ }^{3,4}$, Kelsey J. Ramirez ${ }^{2}$, Gregg T. Beckham (1) ${ }^{2,4}$ \& Yuriy Román-Leshkov (i) ${ }^{1}$

The ratio of syringyl (S) and guaiacyl (G) units in lignin has been regarded as a major factor in determining the maximum monomer yield from lignin depolymerization. This limit arises from the notion that $\mathrm{G}$ units are prone to $\mathrm{C}-\mathrm{C}$ bond formation during lignin biosynthesis, resulting in less ether linkages that generate monomers. This study uses reductive catalytic fractionation (RCF) in flow-through reactors as an analytical tool to depolymerize lignin in poplar with naturally varying $S / G$ ratios, and directly challenges the common conception that the $\mathrm{S} / \mathrm{G}$ ratio predicts monomer yields. Rather, this work suggests that the plant controls $\mathrm{C}-\mathrm{O}$ and $\mathrm{C}-\mathrm{C}$ bond content by regulating monomer transport during lignin biosynthesis. Overall, our results indicate that additional factors beyond the monomeric composition of native lignin are important in developing a fundamental understanding of lignin biosynthesis.

\footnotetext{
${ }^{1}$ Department of Chemical Engineering, Massachusetts Institute of Technology, 25 Ames St, Cambridge, MA 02139, USA. ${ }^{2}$ National Bioenergy Center, National Renewable Energy Laboratory, 15013 Denver W Pkwy, Golden, CO 80401, USA. ${ }^{3}$ Oak Ridge National Laboratory, 1 Bethel Valley Rd, Oak Ridge, TN 37830, USA. ${ }^{4}$ The Center for Bioenergy Innovation, Oak Ridge National Laboratory, Oak Ridge, TN 37830, USA. ${ }^{5}$ These authors contributed equally: Eric M. Anderson, Michael L. Stone. Correspondence and requests for materials should be addressed to G.T.B. (email: Gregg.beckham@nrel.gov) or to Y.R.-L. (email: yroman@mit.edu)
} 
T he success of second-generation biorefineries hinges on the effective removal and utilization of the lignin fraction of biomass (ranging from 12 to $32 \mathrm{wt} \%$ depending on the plant species) $)^{1}$. Lignin is a poly-aromatic polymer contained in the cell wall of the plant, which provides structural stability, aids in water transport, and assists in preventing microbial attack of plant cells ${ }^{2,3}$. Accordingly, lignin contributes to the overall recalcitrance of biomass and must be separated before carbohydrates can be successfully and selectively converted into fuels and chemicals $^{3-6}$.

Lignin is created by the polymerization of three monomers, sinapyl alcohol, coniferyl alcohol, and p-coumaryl alcohol, which are synthesized from phenylalanyl and tyrosine in the cytoplasm ${ }^{7,8}$. The plant transports monomers to the cell wall where they undergo free radical coupling reactions creating a variety of $\mathrm{C}-\mathrm{O}$ and $\mathrm{C}-\mathrm{C}$ linkages (Fig. 1). This polymerization is mediated by peroxidase and laccase enzymes that form radicals on the phenolic group. By resonance, the radical is shared by the 5,1 , and $\beta$ position of the monomer ${ }^{9}$ and coupling reactions at any of these positions lead to polymers linked via $\mathrm{C}-\mathrm{O}$ bonds ( $\beta$ $\mathrm{O}-4)$ and $\mathrm{C}-\mathrm{C}$ bonds $(\beta-5,5-5, \beta-1$, and $\beta-\beta)$. The $\beta-\mathrm{O}-4$ bonds are the most abundant and, due to their labile nature, are key for the depolymerization of lignin. The generation of one monomer unit in depolymerization requires cleavage of two $\beta-\mathrm{O}-4$ bonds, one at each side of the aromatic unit. Therefore, a small number of $\mathrm{C}-\mathrm{C}$ linkages in the lignin structure can reduce the maximum theoretical monomer content. For example, in the lignin polymer shown in Fig. 1, a $\beta-O-4$ content of $69 \%$ only yields a maximum monomer yield of $36 \%$. Monomeric units from lignin depolymerization have been shown to be highly valuable as they offer a diverse platform to synthesize chemicals ${ }^{10-20}$ and functional replacements for conventional polymers ${ }^{21-25}$.

Influencing lignin biosynthesis to favor the production of sinapyl alcohol (S-unit) relative to coniferyl alcohol (G-unit) is hypothesized to increase the $\beta-\mathrm{O}-4$ content in lignin. Sinapyl alcohol has a methoxy group at the 5 position of the aromatic ring, thus preventing the formation of $\beta-5$ and $5-5 \mathrm{C}-\mathrm{C}$ linkages. Indeed, a higher $S / G$ ratio in lignin has been shown to produce higher monomer yields using reductive catalytic fractionation (RCF) as a depolymerization method, as can be seen in Supplementary Fig. 1, where we compiled a variety of monomer yields found in the literature across a vast range of $S / G$ ratios from different natural and genetically modified feedstocks. Van den Bosch et al. ${ }^{26}$ showed that birch lignin $(\mathrm{S} / \mathrm{G}=3)$ subjected to RCF at $523 \mathrm{~K}$ produced a monomer yield of $50 \mathrm{C}-\mathrm{mol} \%$, while poplar $(\mathrm{S} / \mathrm{G}=1.5)$ and a softwood $(\mathrm{S} / \mathrm{G}=0.05)$ produced yields of 44 and $21 \mathrm{C}-\mathrm{mol} \%$, respectively. Similarly, reports on genetically modified poplar with high or low S/G ratios showed a slight correlation between $S / G$ and monomer yields. Shuai et al. showed that genetically modified poplar $(\mathrm{S} / \mathrm{G}=58)^{27}$ produced a monomer yield of $78 \mathrm{wt} \%$ when depolymerized using $\mathrm{RCF}^{28}$. Interestingly, Parsell et al. ${ }^{29}$ observed a lower monomer yield of 36 wt\% for an F5H-modified poplar with an S/G of 2.7 and Luo et al. ${ }^{30}$ observed a yield of $32.5 \mathrm{wt} \%$ for a genetically modified low-S poplar $(S / G=0.51)$. Despite seeing trends across both different species and genetically modified poplar, it is difficult to isolate the effect of $S / G$ ratio on monomer yields from the effects resulting from plant genotype and genetic engineering. We reasoned that the effect of $S / G$ ratio within natural variants of poplar would allow us to better isolate the effect of $S / G$ ratio from other factors.

Although many active stabilization methods have been developed to extract and simultaneously depolymerize lignin into stabile aromatic units ${ }^{6,31,32}$, RCF is effective at achieving neartheoretical lignin monomer yields from $\beta-\mathrm{O}-4$ bond cleavage. It works through a solvolytic extraction of biomass followed by reductive cleavage of ether linkages in lignin over a redox active catalyst ${ }^{33}$. Typically, RCF is performed in a polar protic solvent ${ }^{34,35}$ with hydrogen gas or a hydrogen donor ${ }^{36-38}$ as a reductant and either $\mathrm{Ru}^{26}, \mathrm{Pd}^{39}$, or $\mathrm{Ni}^{36,40,41}$ catalysts at $180-250^{\circ} \mathrm{C}$. RCF depolymerizes lignin by selectively cleaving all $\beta$-O-4 linkages within the lignin polymer to produce a stable mixture of monomeric and oligomeric alkyl phenols while preserving carbohydrates as a solid $37,42,43$. Therefore, the distribution of monomeric and oligomeric phenols can be easily mapped to the native lignin structure of the plant.

In this study, we use RCF to investigate the impact of the $S / G$ ratio on the production of monomers using natural poplar variants with $S / G$ contents ranging from 1.41 to 3.60 , or percent $S$ content of $58.5 \%$ to $78.3 \%$ (Table 1$)^{44}$. These five samples capture the range of $S / G$ ratios present in a naturally variant population of over 1000 poplar trees ${ }^{45}$. RCF experiments were performed in flow-through reactors to obtain time- and composition-resolved extraction profiles. Additionally, batch experiments were performed at near complete lignin extraction. The oligomeric fractions were analyzed by heteronuclear single quantum coherence (HSQC) NMR spectroscopy to obtain the time-averaged S/G ratio. Additionally, the oligomers were derivatized by silylation and analyzed by gas chromatography-mass spectrometry (GCMS) to obtain a qualitative distribution of C-C linkages within the dimeric fraction. These time-resolved data on both the monomeric and oligomeric fractions led to insights on the $\mathrm{C}-\mathrm{C}$ bonding patterns of S-units that result in a decreased dependency of monomer yields on the S/G ratio than was previously hypothesized in the literature ${ }^{6}$.

\section{Results}

Flow-through and batch RCF of poplar natural variants. RCF was performed with five poplar natural variants in a dual-bed flow-through reactor to test the hypothesis that higher S content should yield more monomers. The solvolysis bed was loaded with whole biomass corresponding to $0.26 \mathrm{~g}$ of lignin (Table 1 ). The reduction bed was loaded with $0.3 \mathrm{~g}$ of a $50 / 50 \mathrm{mix}$ by weight of $15 \mathrm{wt} \% \mathrm{Ni} / \mathrm{C}$ and $\mathrm{SiO}_{2}$. This catalyst loading ensured near complete fractionation and reduction of the lignin over the catalyst bed as determined in our previous study ${ }^{46}$. Thus, under these conditions, the rate of monomer production was limited by the rate of solvolysis or lignin extraction as opposed to the rate of catalytic reduction ${ }^{33}$. Both beds were operated at $190^{\circ} \mathrm{C}$ and 60 bar with a methanol and hydrogen flow rate of 0.5 and $50 \mathrm{~mL} \mathrm{~min}^{-1}$, respectively. At $6 \mathrm{~h}$ on stream, the cumulative monomer yield was approximately $23 \mathrm{wt} \%$ from samples with an S/G of $1.41,2.35,3.48$, and 3.60 while the one with an S/G of 1.69 produced a monomer yield of $20 \mathrm{wt} \%$ (Fig. $2 \mathrm{a}$ ). The yields were calculated relative to total lignin content in the biomass initially, defined as the sum of Klason and acid-soluble lignin contents (lignin content summarized in Supplementary Table 1). The total mass isolated from an RCF run was subjected to extractions with dichloromethane/water to remove sugars. The resulting oil containing both monomers and oligomers, defined as lignin oil, was used as a metric to describe the extent of lignin extraction. Minimal losses of lignin products during DCM extraction were confirmed using gas chromatography-flame ionization detector (GC-FID) analysis of the aqueous phase (Supplementary Fig. 2). Extent of lignin extraction was comparable for all samples with $54,50,52,51$, and $53 \mathrm{wt} \%$ of lignin extracted for $\mathrm{S} / \mathrm{G}$ ratios of $1.41,1.69,2.35,3.48$, and 3.60 , respectively. The $\mathrm{S} / \mathrm{G}$ ratio of the monomers produced also show only a weak correlation with the $\mathrm{S} / \mathrm{G}$ ratio of the biomass sample (Fig. $2 \mathrm{~b}$ ).

Importantly, these same trends were observed at experimental conditions resulting in nearly complete lignin extraction. 


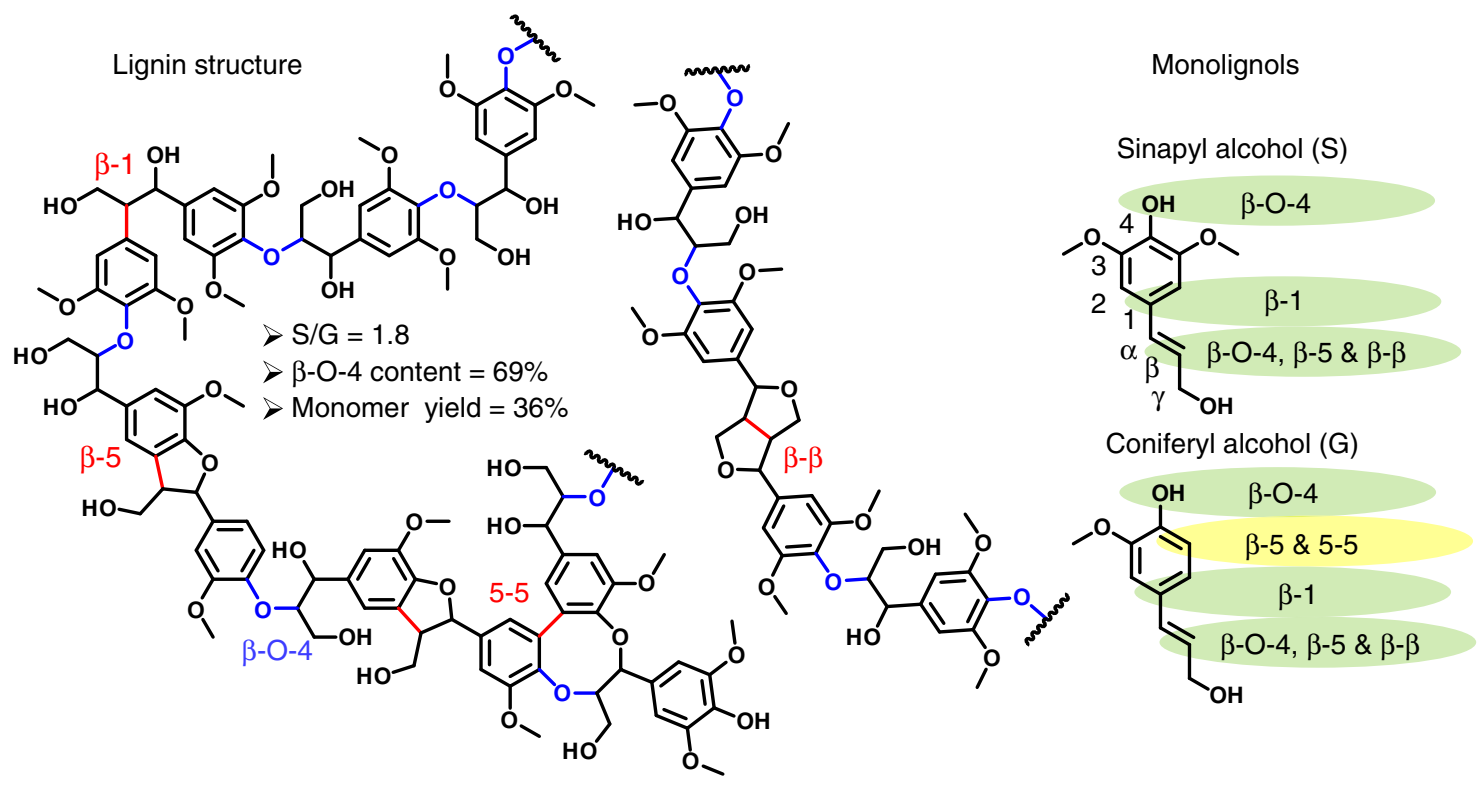

Fig. 1 Lignin structure overview. The two primary monomers, sinapyl alcohol and coniferyl alcohol, shown with the different reacting carbons highlighted with the appropriate $\mathrm{C}-\mathrm{O}$ or $\mathrm{C}-\mathrm{C}$ bonds that can form. A hypothetical lignin structure is shown with each type of bond as well as the calculated $\mathrm{S} / \mathrm{G}$ ratio, $\beta-\mathrm{O}-4$ content, and monomer yield

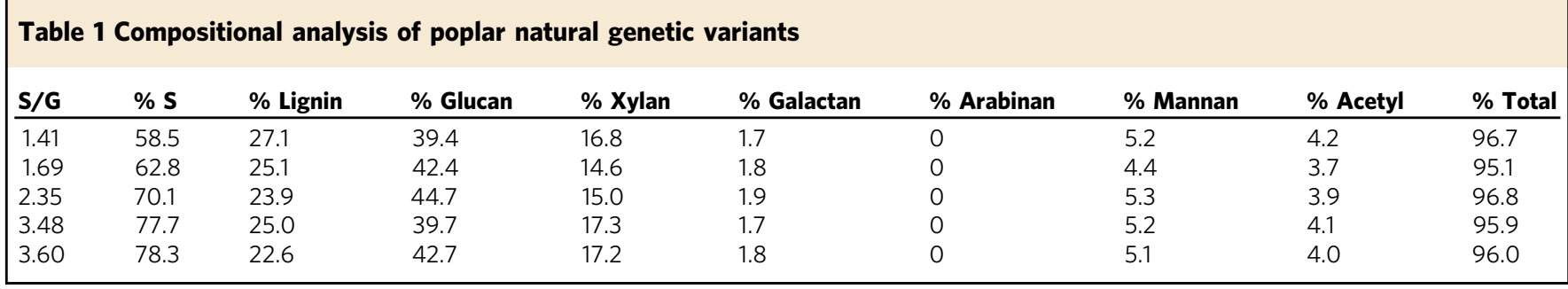

Specifically, batch RCF experiments performed with supercritical methanol resulted in $80-90 \%$ extraction and depolymerization of the lignin within the biomass samples. At these high lignin extraction levels, the monomer yields were 34.4, 31.8, 33.0, 31.6, and $30.0 \mathrm{wt} \%$ for the same samples with an increasing $\mathrm{S} / \mathrm{G}$ ranging from 1.41 to 3.60 (Fig. 2c). Notably, the sample with the highest monomer yield had the lowest $S / G$ ratio and the sample with the lowest yield had the highest S/G ratio. The final S/G ratio of the monomers showed similar trends to those at fractional conversion. The invariance in monomer yields with $\mathrm{S} / \mathrm{G}$ in the native plants is strong evidence that there are differences in the distribution of $\mathrm{C}-\mathrm{C}$ linked $\mathrm{S}$ and $\mathrm{G}$ units in the oligomer fraction.

Furthermore, to confirm that the lack of correlation between monomer yields and the $S / G$ ratio was not caused by the RCF method or by limitations due to catalyst choice, we performed batch RCF with a commercial ruthenium on carbon $(\mathrm{Ru} / \mathrm{C})$ catalyst as well as thioacidolysis on each sample. Thioacidolysis is a common lignin analytical technique used to measure the relative content of lignin monomers bound by $\beta-\mathrm{O}-4$ linkages ${ }^{47-49}$. These data, summarized in Supplementary Tables 2 and 3 and Supplementary Figs. 4 and 5, show that neither RCF with $\mathrm{Ru} / \mathrm{C}$ or thioacidolysis yields correlate with the S/G ratio. An important metric to directly compare the depolymerization efficiency of $\mathrm{Ru} / \mathrm{C}$ with $\mathrm{Ni} / \mathrm{C}$ is the monomer/oil ratio (i.e. the weight fraction of the lignin oil made up by monomers). While $\mathrm{Ru} / \mathrm{C}$ generated slightly higher monomer/oil ratios than $\mathrm{Ni} / \mathrm{C}$, it showed no trend in monomer/oil ratio across the $S / G$ range.
These experiments confirmed that the conclusions drawn from the $\mathrm{Ni} / \mathrm{C} \mathrm{RCF}$ results are valid, despite slight variations in results between different depolymerization methods, and validate the use of flow-through RCF as an analytical technique.

Characterization of the lignin oils. While the oligomeric fraction of the lignin oil requires more detailed characterization, it offers critical information, such as the molecular weight of lignin fragments, the S/G ratio of the oligomers, and even the identity of $\mathrm{C}-\mathrm{C}$ linkages in the oligomers. To obtain enough material for analysis, we collected the oil as time-averaged samples at binned times on stream of $1,2-3$, and $4-6 \mathrm{~h}$. The molecular weight of the lignin oil was determined by gel permeation chromatography (GPC), with the samples run at identical lignin oil concentrations to enable comparison. Generally, for all biomass samples, high monomer yields were obtained in earlier time points while high oligomers yields were observed at later time points (Fig. 3a). At $1 \mathrm{~h}$ on stream, nearly $60 \%$ of the lignin oil consisted of monomers. Subsequently, the monomer-to-oil ratio steadily decreased as the reaction progressed ultimately leading to $70 \%$ of the lignin oil consisting of oligomers at 4-6 h. This trend is mirrored in the GPC (Fig. 3b and Mn, Mw, PD summarized in Supplementary Table 4). Initially, all lignin oils contained fragments under $1000 \mathrm{Da}$, but at later times, a new peak appeared at $1000 \mathrm{Da}$ that extended out to $2000 \mathrm{Da}$. Additionally, the lowest molecular weight peak associated with monomer content drastically decreased as the reaction progressed. 
a

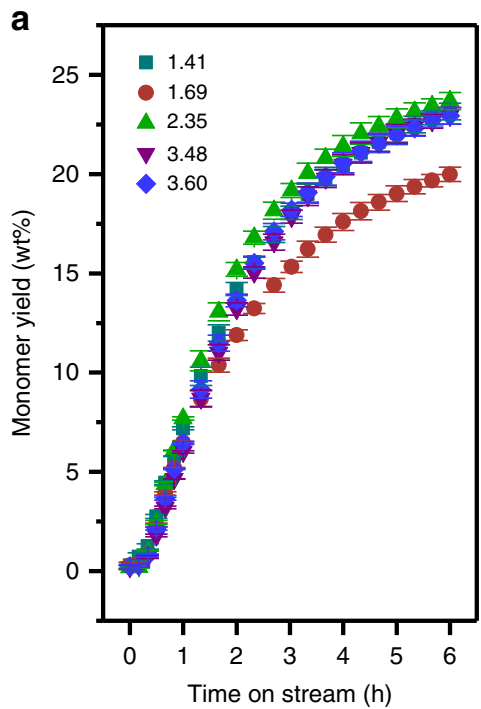

b

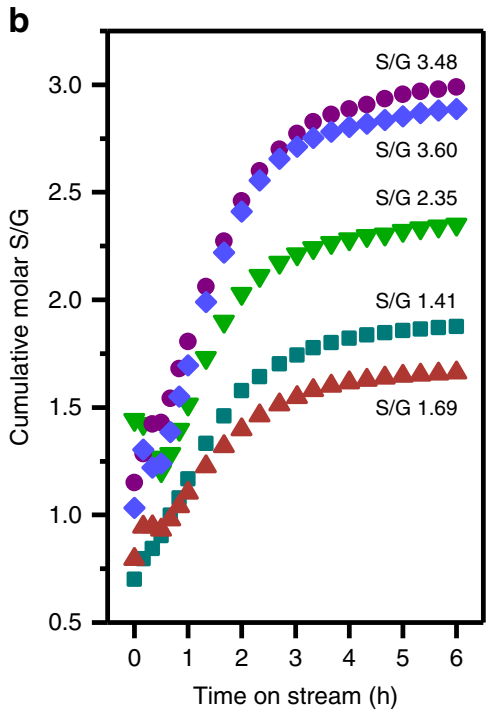

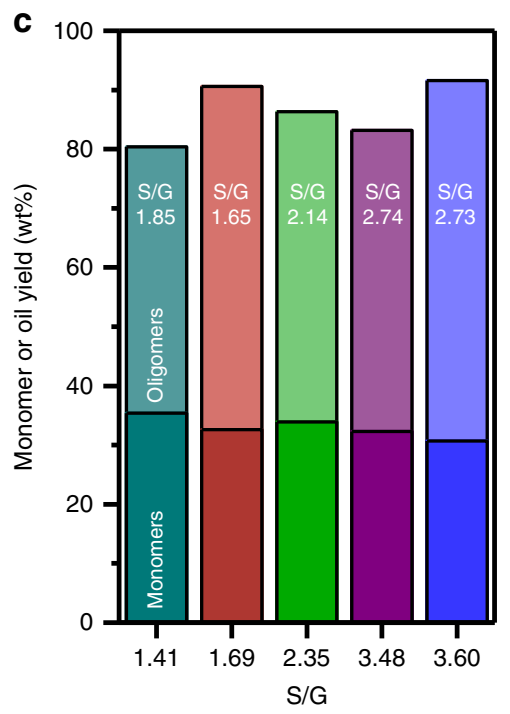

Fig. 2 Yields and S/G ratios from flow-through and batch RCF reactions for poplar natural variants. a Cumulative monomer yields for all five poplar natural variants (relative to Klason + acid-soluble lignin in the biomass sample). Error bars are $99 \%$ confidence intervals for each point generated from a replicate of the experiment on $S / G=1.69$ (see Supplementary Fig. 3). b The cumulative $S / G$ ratio calculated from the molar ratio of monomers observed from the $\mathrm{RCF}$ reaction. The S/G ratios calculated from monomers recovered are shown in text on the bars. Reaction conditions: $0.96-1.15 \mathrm{~g}$ of poplar wood (0.26 $\mathrm{g}$ lignin), $0.3 \mathrm{~g}$ of $15 \% \mathrm{Ni} / \mathrm{C}\left(50 / 50 \mathrm{SiO}_{2}\right), 190^{\circ} \mathrm{C}$ both beds, $0.5 \mathrm{~mL} \mathrm{~min}-1 \mathrm{MeOH}, 50 \mathrm{~mL} \mathrm{~min}^{-1} \mathrm{H}_{2}$ at 60 bar. c Final yield of both monomers and oligomers obtained from a batch reaction. Batch Conditions: $0.96-1.15 \mathrm{~g}$ of poplar wood, $0.15 \mathrm{~g} 15 \% \mathrm{Ni} / \mathrm{C}, 50 \mathrm{~mL} \mathrm{MeOH}, 250{ }^{\circ} \mathrm{C}, 700 \mathrm{RPM}$, and $30 \mathrm{bar}$ of $\mathrm{H}_{2}$ (STP)

a

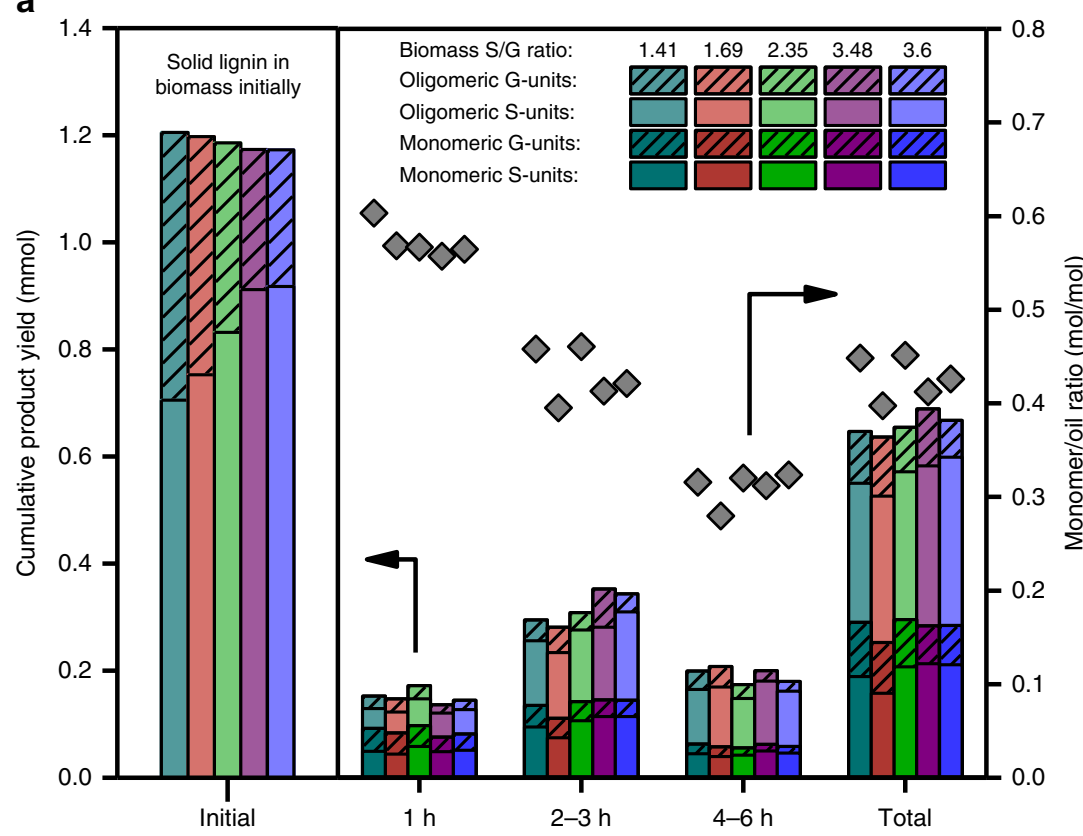

b

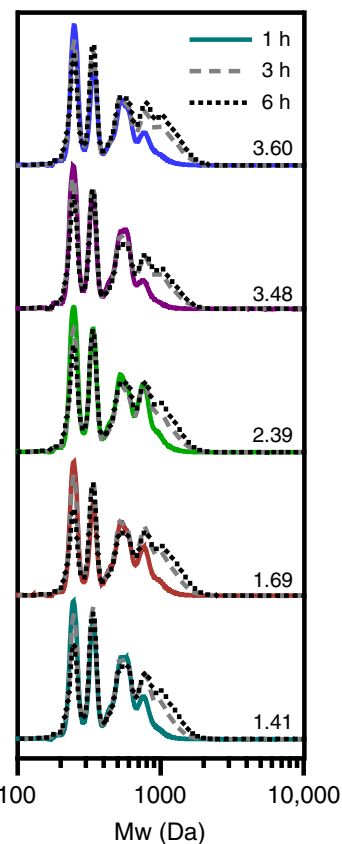

Fig. 3 Characterization of the oligomeric fraction of lignin oil produced from flow-through RCF. a Mole balance of $\mathrm{S}$ and $\mathrm{G}$ aromatic units in the monomeric and oligomeric species in lignin oil. The molar monomer-to-oil ratio, which is a measure of lignin fractionation and depolymerization. $\mathbf{b}$ GPC of the lignin oils from different biomass samples at different RCF extraction times

The S/G ratio of the entire lignin oil was determined with HSQC-NMR spectroscopy by calculating the molar ratio of syringyl to guaiacyl units obtained from integrating the correlation peaks of $\mathrm{S}_{2,6}, \mathrm{~S}_{2,6}^{\prime}$ (oxidized S-unit), and $\mathrm{G}_{2}$ (refs. ${ }^{50,51}$ ). The correlations used for the $S_{2,6}$ position were 105.2/6.38 and 102.9/ $6.57 \mathrm{ppm}$, while 105.9/7.22 ppm was used for $\mathrm{S}_{2,6}^{\prime}$. Total integrals of those peaks corresponded to two correlations (i.e., the 2,6 position in the syringyl aromatic ring). The correlations for the
$\mathrm{G}_{2}$ position were at $111.1 / 6.65$ and $109.5 / 6.52 \mathrm{ppm}$, and their integrals corresponded to one correlation (i.e., the 2-position in the guaiacyl aromatic ring). An example of the HSQC-NMR analysis is shown in Supplementary Fig. 6. Given that the molar quantities of monomeric $S$ and $G$ units in the oil were readily quantified using GC, we were then able to calculate the molar quantities of $S$ and $G$ units in the oligomeric fractions using Eqs. (1) and (2), respectively. The derivation of these equations is 
shown in the Supplementary Methods, and relies on the molecular weight of the monomeric units in lignin oil, which we approximated as propyl syringol and propyl guaiacol. A similar method was used to determine the molar quantities of $S$ and $G$ units in the proto-lignin in the solid biomass samples to generate the bars on the left side of Fig. 3a (full details and equations in the Supplementary Methods).

$$
\begin{aligned}
\mathrm{Mol}_{\mathrm{S}, \text { Olig }} & =\frac{\mathrm{S}}{\mathrm{G}} \frac{\mathrm{Mass}_{\mathrm{RCF} \text { Oil }}}{\left(\frac{\mathrm{S}}{\mathrm{G}} * \mathrm{Mw}_{\mathrm{S}}+\mathrm{Mw}_{\mathrm{G}}\right)}-\mathrm{Mol}_{\mathrm{S}, \mathrm{Mon}}, \\
\mathrm{Mol}_{\mathrm{G}, \text { Olig }} & =\frac{\mathrm{Mass}_{\mathrm{RCF} \text { Oil }}}{\left(\frac{\mathrm{S}}{\mathrm{G}} * \mathrm{Mw}_{\mathrm{S}}+\mathrm{Mw}_{\mathrm{G}}\right)}-\mathrm{Mol}_{\mathrm{G}, \mathrm{Mon}} .
\end{aligned}
$$

To best compare the partition of $\mathrm{S}$ and $\mathrm{G}$ units between monomer and oligomer fractions, we used a mole fraction variable $\left(x_{\mathrm{S} \text { or } \mathrm{G}}\right)$ defined in Eq. (3). It represents the fraction of $S$ (or $G$ ) units present in the product mixture that are bound as oligomers relative to the total number of $S$ (or $\mathrm{G}$ ) units in the mixture (i.e. monomers + oligomers). This value can also be understood as a partition coefficient of S (or G) units into the oligomer fraction. Notably, when the moles of $S$ or $G$ in the oligomer fraction are normalized by the total $S$ or $G$ content in the lignin oil, the trends across all S/G variants collapse to a single trend (Supplementary Table 5).

$$
x_{\mathrm{S}(\mathrm{G})}(\text { Moles })=\frac{\text { Oligomers }_{\mathrm{S}(\mathrm{G})}}{\text { Oligomers }_{\mathrm{S}(\mathrm{G})}+\text { Monomers }_{\mathrm{S}(\mathrm{G})}} .
$$

At all time points and for all samples, the $S$ units partitioned into the oligomer fraction more than the $G$ units (Supplementary Fig. 7), and both increased their oligomer fraction content over time. Specifically, during the first hour of extraction, the $\mathrm{C}-\mathrm{C}$ linked oligomers contained $40-50 \%$ of all $\mathrm{S}$ units and only $30-40 \%$ of all $\mathrm{G}$ units. At $2-3 \mathrm{~h}$, the S-unit content in the oligomers increased to $50-60 \%$ and the G-unit content increased to $40-50 \%$. At $4-6 \mathrm{~h}, \mathrm{~S}$ content reached $60-70 \%$, while $\mathrm{G}$ content reached $60-65 \%$. Averaging over all time points shows that $60 \%$ of all $\mathrm{S}$ units and $50 \%$ of all $\mathrm{G}$ units existed as $\mathrm{C}-\mathrm{C}$ linked oligomers. These values directly contradict the expected distribution of $\mathrm{S}$ and $\mathrm{G}$ units in $\mathrm{C}-\mathrm{C}$ linked oligomers, since $\mathrm{S}$ units should inherently form less $\mathrm{C}-\mathrm{C}$ bonds during lignin biosynthesis due to a blocked 5 position in the aromatic ring that is responsible for the formation of $\beta-5$ and 5-5 linkages.

Analysis of the dimer fraction of the lignin oils. Given this surprising result, a more detailed analysis of the dimer distribution was necessary to understand what S-S bonds were formed in the oligomer fraction. To study this bonding pattern, the lignin oils from the same five flow-through RCF experiments at 1,2-3, and $4-6 \mathrm{~h}$ on stream were silylated to increase the volatility of the dimeric lignin fragments in the oil. These dimers were then identified by GC-MS and their relative amounts were used to qualitatively understand what $\mathrm{C}-\mathrm{C}$ linkages were present in the native lignin of poplar with different $S / G$ ratios and how they were released at different extraction times. Given inherent limitations in using GC-MS to analyze lignin dimers, we emphasize that the dimer distribution does not show the complete picture of all $\mathrm{C}-\mathrm{C}$ linkages in the oligomer fraction. Indeed, this fraction will also always over-predict the amount of total $\beta-1$ and $\beta-\beta$ linkages in the lignin. These linkages can only form higher $\mathrm{C}-\mathrm{C}$ linked oligomers when coupled with 5-5 fragment.

A total of 18 different dimers were identified featuring a variety of $S-S, G-G$, and $S-G$ units coupled via $\beta-1, \beta-\beta, \beta-5$, and $5-5$ C-C linkages (Fig. 4, Supplementary Figs. 11-15 for fragmentation analysis of newly identified dimers and Supplementary Figs. 16-28 for fragmentation patterns and citations of previously identified dimers) $)^{35,47,52}$. Additional minor variation in dimer composition occurred through deoxygenation of the $\gamma$ hydroxyl group on the lignin side chain, as well as the formation of a functionalized tetrahydronaphthalene dimer. Lu et al. $^{53}$ previously reported this class of dimers as a decomposition product of the $\beta-\beta$ resinol structure while performing derivatization followed by reductive cleavage. This compound is formed by an intramolecular $\alpha$-condensation reaction with the opposing aromatic ring at the 6 position. Additionally, uncondensed $\beta-\beta$ dimers were observed, indicating that the reduction catalyst used in RCF can cleave the ether bonds in the resinol structure.

Identification and integration of the dimer peaks allowed for qualitative trends of coupling partners and linkage types. While the actual concentrations were not determined with this technique, the relative ratios of peak areas within each individual injection provide a method to qualitatively analyze trends. The trends in $S-S, G-G$, and $S-G$ dimers formed as a function of time on stream and native $S / G$ ratio are shown in Fig. 5b. Later time points are shown graphically in Supplementary Fig. 8 with the actual values for each linkage shown in Supplementary Table 6. Importantly, for samples with high native $S / G$ values, $50-60 \%$ of the dimers exist as S-S pairs, $\sim 30 \%$ as mixed S-G dimers, and $\sim 10-20 \%$ as $G-G$ pairs. This result suggests that more $S-S$ coupled dimers are formed as the $S / G$ ratio in the native lignin increases.

To understand the abundance of $\mathrm{C}-\mathrm{C}$ coupled S-units, the distribution of linkage types within each coupling pair was analyzed for each $S / G$ ratio and extraction time. The relative distribution of bonds formed by each coupling pair is shown in Fig. $5 \mathrm{c}$ at $1 \mathrm{~h}$ on stream (additional time points shown in Supplementary Fig. 8). The most common C-C linked dimer was the $\beta-\beta$ linkage, which consisted of approximately $40 \%$ of the observed dimers. The $S-S$ linkage was the most common $\beta-\beta$ dimer with $S-G$ or $G-G$ dimers making only a small fraction of the observed linkages (Supplementary Fig. 8). The $\beta-1$ and $\beta-5$ made up on average an additional $50 \%$ of the dimer distribution. There was no significant trend observed for $\beta-1$ linkages between the different coupling partners. Alternatively, more S-G $\beta-5$ linkages were observed than $\mathrm{G}-\mathrm{G} \beta-5$, which ranged from $50 \%$ to $70 \%$ of all S-G linkages while only $25-40 \%$ of $\mathrm{G}-\mathrm{G}$ linkages were $\beta-5$. 5-5 linkages were also observed in a low amount of $2-5 \%$. Some differences in the distribution of $\mathrm{C}-\mathrm{C}$ linkages were observed over the course of the flow-through extraction. The relative amount of $\beta-\beta$ dimers remained unchanged during reaction. The $\beta-1$ linkages initially made up a higher percentage of the dimer distribution at early times consisting of $30-40 \%$ of the total dimers observed. The occurrence of these linkages steadily decreased at longer extraction times to $20 \%$ of the observed dimers at 4-6h. Conversely, lower amounts of $\beta-5$ bonds were observed at $\sim 30 \%$ abundance at $1 \mathrm{~h}$ which increased to $\sim 50 \%$ at later extraction times. The 5-5 linkages were primarily observed at $1 \mathrm{~h}$ on stream and are barely detected at $2-3$ and $4-6 \mathrm{~h}$.

\section{Discussion}

The differences in monomer yields and lignin composition at different extraction times was unexpected. The initial surge of monomers might be linked to diffusion limitations associated with varying lignin fragment chain lengths. Specifically, the delayed release of larger lignin fragments could be due to incomplete depolymerization, recondensation reactions, or their inherent slower diffusivity through the biomass pores. HSQCNMR spectroscopy showed little $\beta-\mathrm{O}-4$ remaining in the lignin oil isolated at $1 \mathrm{~h}$, and slightly more $\beta-\mathrm{O}-4$ content in the later time points. Additionally, no peaks corresponding to $\beta-\mathrm{O}-4$ dimers 

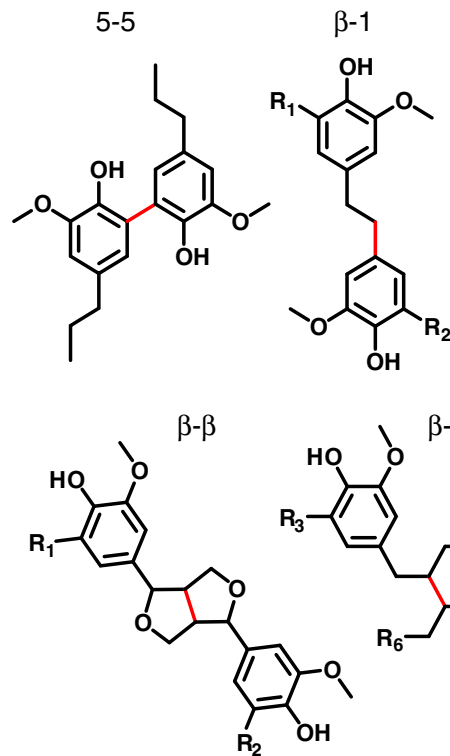<smiles>[2H]CC(Cc1cc([2H])c(O)c(OC)c1)c1cc([2H])c(O)c(OC)c1</smiles>

$\beta-\beta$

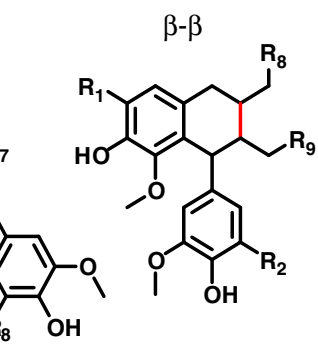

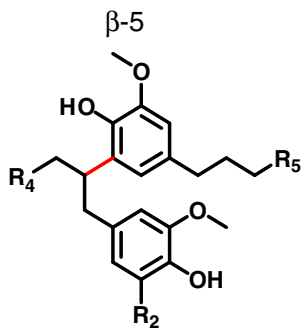

G-G: $R_{1} \& R_{2}=H$

S-G: $\mathrm{R}_{1}=\mathrm{OCH}_{3} \& \mathrm{R}_{2}=\mathrm{H}$

G-S: $R_{1}=H \& R_{2}=\mathrm{OCH}_{3}$

S-S: $\mathrm{R}_{1}=\mathrm{OCH}_{3} \& \mathrm{R}_{2}=\mathrm{OCH}_{3}$

$\beta-1: R_{3}=H$

$\beta-1 \gamma-\mathrm{OH}: \mathrm{R}_{3}=\mathrm{OH}$

$\beta-5: \mathrm{R}_{4}=\mathrm{H} \mathrm{R}_{5}=\mathrm{H}$

$\beta-5 \gamma-\mathrm{OH}: \mathrm{R}_{4}=\mathrm{OH} \mathrm{R} \mathrm{R}_{5}=\mathrm{H}$

$\beta-5 \gamma-\mathrm{OH}: \mathrm{R}_{4}=\mathrm{H} \mathrm{R}_{5}=\mathrm{OH}$

$\beta-\beta 2 \gamma-\mathrm{OH}: \mathrm{R}_{6}=\mathrm{OH} \mathrm{R} \mathrm{R}_{7}=\mathrm{OH}$

$\beta-\beta \alpha-2: \mathrm{R}_{6}=\mathrm{OH} \mathrm{R} \mathrm{R}_{7}=\mathrm{OH}$

Fig. 4 Structures of observable dimers from flow-through RCF. Each dimer shown was identified in the RCF lignin oil using derivatization followed by GC-MS. Red lines indicate the carbon-carbon bond present between two monolignols, which corresponds to the naming convention. Each variation in functionalization (that was identified in the lignin oil) for each dimer is shown in the list on the right

were observed, which previously were observed for incomplete hydrogenolysis ${ }^{46}$. Because of the low $\beta-\mathrm{O}-4$ content in the RCF products, it is unlikely that incomplete depolymerization of lignin was the cause of the observed trends. Recondensation of lignin occurs through a dehydration step at the a-carbon of monomers, which generates a carbocation that is susceptible to attack from the aromatic ring of other lignin fragments. Indeed, stabilization strategies have been developed to protect this position and reduce recondensation. Lancefield et al. showed that lignin extracted in alcohols resulted in the addition of the alcohol to the a carbon of monomers to prevent condensation reactions ${ }^{30,54}$. Shuai et al. ${ }^{28}$ also showed that formaldehyde treated lignin created a dioxane ring with the hydroxyls at the $\alpha$ and $\gamma$ positions of monomers, which prevents deleterious dehydrations from occurring. Shuai et al. also showed that monomer yields from a formaldehydestabilized lignin were identical to those produced from direct RCF of the same biomass. In this work, we demonstrated similar trends using either $\mathrm{Ni} / \mathrm{C}$ or commercial $\mathrm{Ru} / \mathrm{C}$ catalysts, indicating the results obtained were not caused by the type of catalyst used. Therefore, the supercritical RCF experiments performed within this study should indicate a true monomer yield for each natural variant, ruling out recondensation as the cause of the observed trends.

Comparing the data collected in supercritical batch and flowthrough experiments in this work further supports the claim that variation in monomer yields due to condensation is unlikely. On average, the monomer-to-oil ratio from supercritical RCF experiments was 0.38 , while flow-through RCF had a monomerto oil ratio of 0.42 implying a similar amount of depolymerization. If lignin condensation had occurred, the monomer-to-oil ratio of 0.6 observed at $1 \mathrm{~h}$ on stream would be the expected result from the supercritical RCF runs. Additionally, the only condensation product observed by GC-MS in the dimer region was the intramolecular condensation of the resinol. Taken together, these data indicate that differences in the molecular weight distributions as a function of time are most likely not caused by repolymerization during extraction.

The most probable factor influencing the temporal dependence of monomer yields and types of dimers observed is differences in chain length. Diffusion of lignin in the internal pores of wood particles would allow for small chains to appear early in the extraction while long chains would lag behind. The high occurrence of $\beta-1$ linkages observed at early times supports this hypothesis, because $\beta$-1 linkages can form from the fragmentation of a growing chain to start a new polymer chain ${ }^{52}$. As these fragments are formed later in the lignin synthesis, they are likely shorter than those chains formed at the beginning of the process. The increase in $\beta-5$ bonds over the course of the extraction also supports this hypothesis, since these are $\mathrm{C}-\mathrm{C}$ linkages formed during chain growth. The high amount of $\beta-\beta$ linkages present can only act as starting points to chains because $\beta-\beta$ bonds cannot form on a growing chain. The hypothesis of chain diffusion also could explain the initially high monomer yields. The monomer yield will have some dependence on chain length. At two extremes, six 4-unit chains-each with an average of 50\% $\beta$-O-4 content-will produce a $38-50 \%$ yield of monomers (depending on the location of the $\mathrm{C}-\mathrm{C}$ bonds), while a single chain with 24 units and a $50 \% \beta-\mathrm{O}-4$ content will generate $25 \%$ of monomers. This concept was illustrated by Galkin et al. ${ }^{55}$ and is based on the idea that monomer production requires $\beta-\mathrm{O}-4$ bonds at both the 4 - and $\beta$-position of the monomer unit in the polymer chain. In short polymers, terminal positions of the chain are important, while in longer chains their contribution is negligible.

The consistent monomer yields between all of the different natural variants implies there may be some degree of control exerted by the plant that influences the types of linkages formed in the polymerization process. Lignin biosynthesis is dictated by the generation of radicals by peroxidase or laccase enzymes. Radical coupling is fast, and thus the only handle to manipulate the chemistry from a kinetically controlled polymerization is the concentration of the monomers in the cell wall ${ }^{56}$. In vitro experiments to generate dehydrogenase polymers (DHP) have been used to generate synthetic lignin. Batch experiments have been performed with coniferyl and sinapyl alcohol. High monomer concentrations led to the formation of $\mathrm{C}-\mathrm{C}$ linked dimers with $\beta-5$ formed from coniferyl alcohol and $\beta-\beta$ dimers from sinapyl alcohol ${ }^{57,58}$. In similar DHP experiments, coniferyl alcohol was slowly added to the reactor maintaining a low 
a
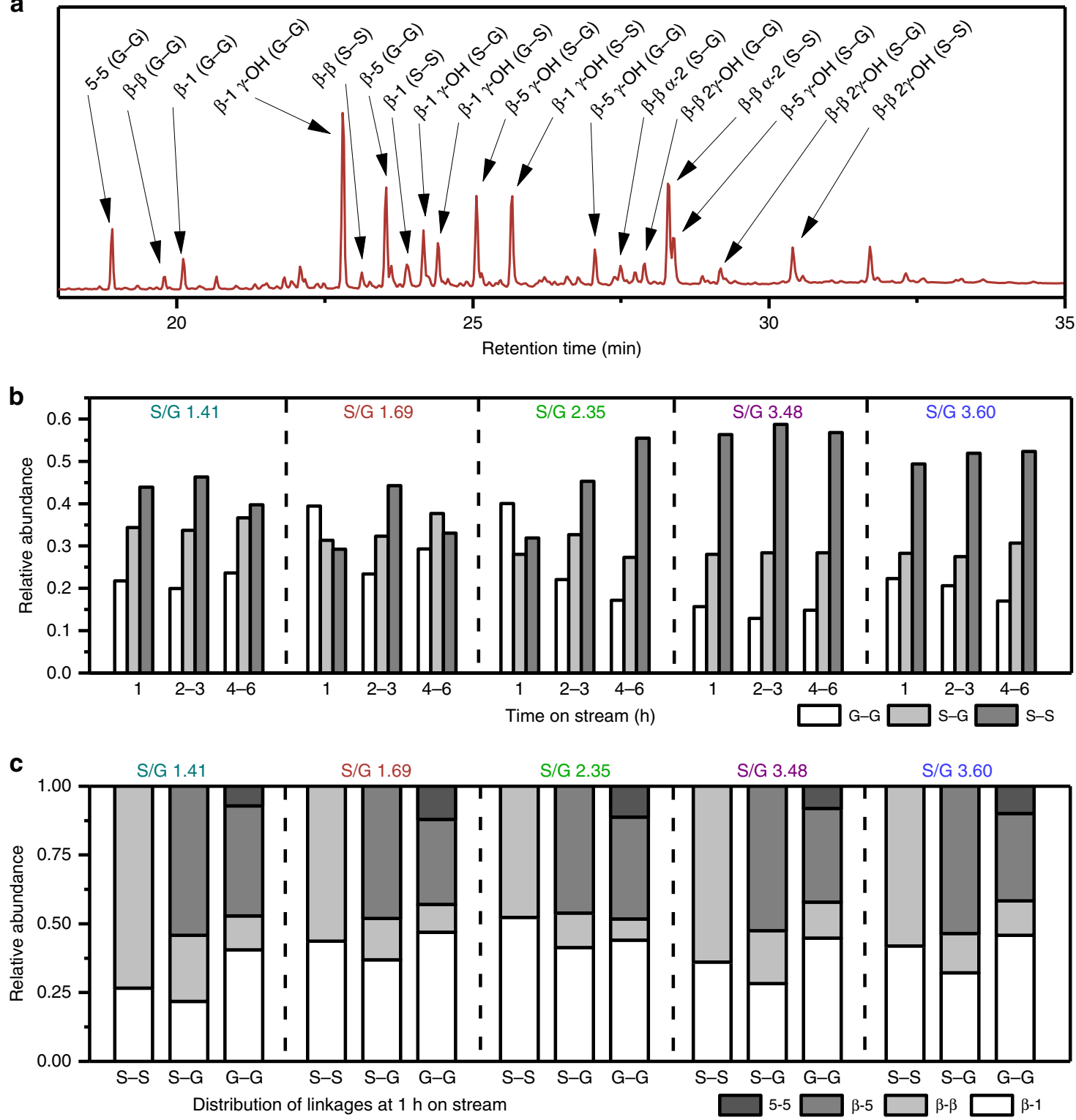

Fig. 5 Distribution of C-C linked dimers observed from flow-through RCF reactions. a Chromatogram from a representative GC-MS run with a silylated lignin oil (specifically, $\mathrm{S} / \mathrm{G}=1.69$ at $1 \mathrm{~h}$ on stream). The intensity of the peaks measured in total ion counts. $\mathbf{b}$ The relative occurrence of the different coupling partners at different times on stream as determined by relative GC-MS total ion count peak areas. c The relative distribution of linkage types with in each monomers coupling pair as determined by relative GC-MS total ion count peak areas. Note that all dimer analysis was done on the same samples as those shown in Figs. 2 and 3

concentration. The low concentration led to nearly a $50 \%$ yield of $\beta$-O-4 linked dimers. Furthermore, when a dialysis membrane was used with both sinapyl and coniferyl alcohol, an insoluble polymer was generated exhibiting similar properties to lignin ${ }^{59,60}$. The importance of monomer delivery rate was shown computationally by van Parijs et al. ${ }^{61}$ who demonstrated that decreasing the influx of monolignols in a lignin polymerization model increased the amount of $\beta$-O- 4 formation by favoring the growth of longer chains and decreasing dimerization. Density functional theory calculations on the energetics of lignin monomer coupling align with these observations, showing that dimerization of two $S$ units will kinetically favor the formation of $\beta-\beta$ bonds ${ }^{62}$. Thus, during lignin biosynthesis, it is plausible that high sinapyl alcohol concentrations relative to the number of growing chains will lead to $\beta-\beta$ formation, while a low sinapyl alcohol concentration during lignification would likely lead to formation of $\beta$-O-4 in a strictly syringyl polymer. This concept, illustrated in Fig. 6, was also shown experimentally by Stewart et al. ${ }^{27}$ who found that genetically modified poplar with $97.5 \% \mathrm{~S}$ showed a significant increase in levels of $\beta-\beta$ linkages (relative to native S-levels in wild-type trees), but an insignificant increase in $\beta$-ether levels ${ }^{27}$. Therefore, the consistent monomer yields that we observed for a range of $S / G$ values could be caused by manipulation of monomer concentrations by the plant to control lignin structure and composition leading to similar lignin in different natural variants. Broadly, monomer concentrations during lignification appear to be an important variable to consider when designing lignin for depolymerization in addition to the $S / G$ ratio.

The results of the study contained herein show that there is no correlation between $S / G$ ratio and monomer yields within the range of $S / G$ ratios in the naturally variant poplar population. All data were collected from only five poplar natural variants with 

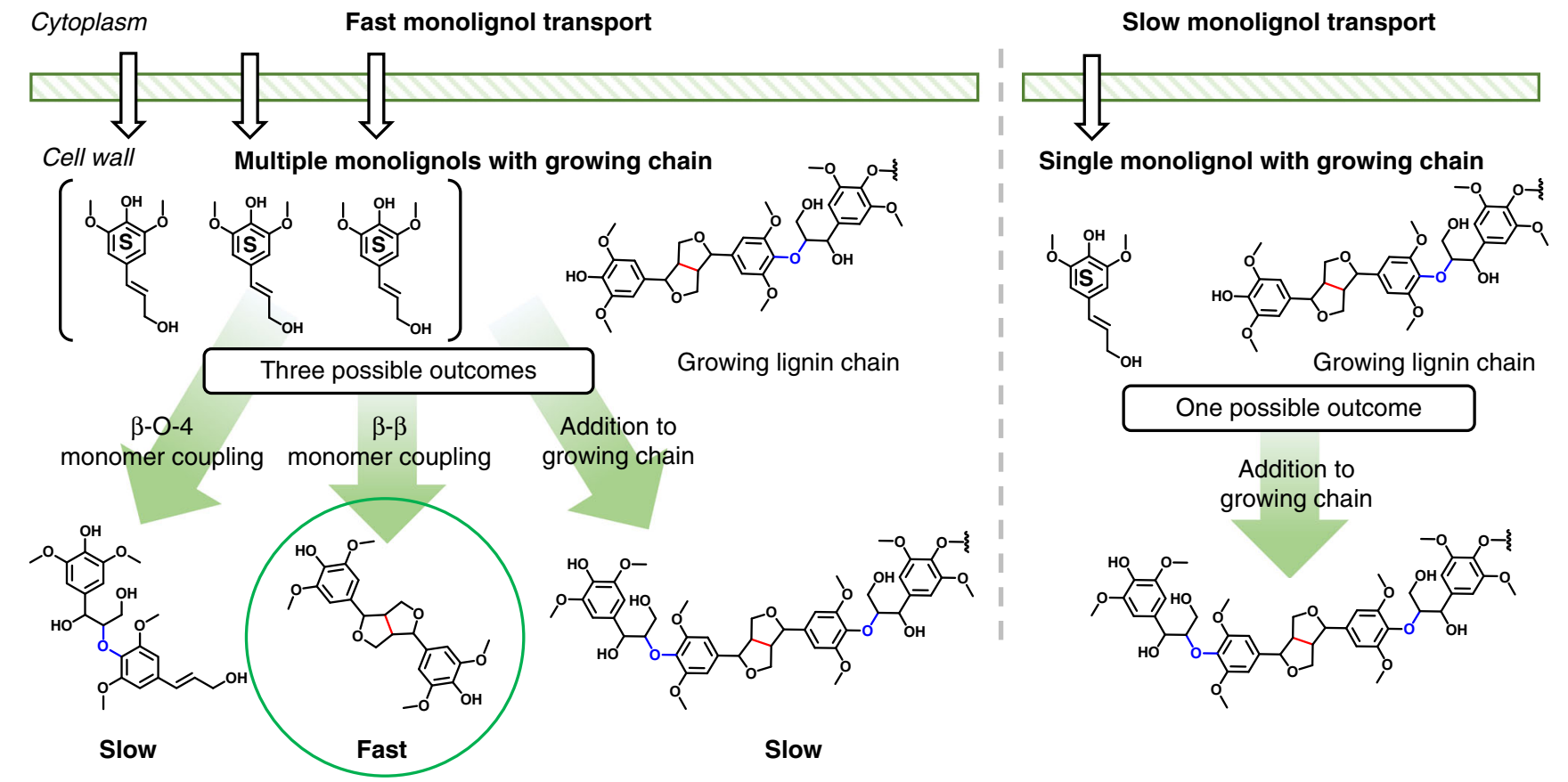

Addition to growing chain

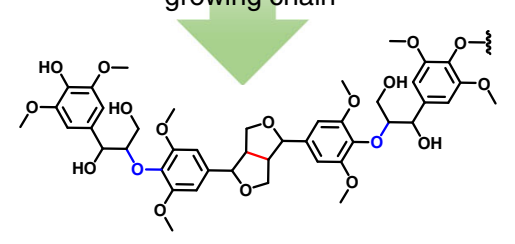

Fig. 6 Illustration of monomer concentration influence on bond formation during lignification. In the case of fast monomer transport from the cytoplasm to the cell wall, monomers can couple together to form dimers, or add to growing lignin chains. In the case of slow monomer transport, if an $\mathrm{S}$ monomer can only add to a growing chain that already contains a $\beta-\beta$ bond, it must form a $\beta-\mathrm{O}-4$ ether bond

differing $S / G$ ratios. Indeed, several other parameters could influence lignin bond formation, including pore structure, plant cell wall microstructure, and lignin carbohydrate linkages ${ }^{45,63}$. In subsequent studies, we will employ a larger population of natural variants to perform multi-variate studies in order to understand to what extent other factors truly influence lignin depolymerization.

The lignin in a series of natural poplar variants with lignin S/G ratios ranging from 1.41 to 3.60 was extracted and depolymerized using RCF in flow-through reactors. Surprisingly there was found to be no correlation between $S / G$ ratio and monomer yields in a flow-through reaction at $50 \%$ lignin extraction. Furthermore, when operating at $80-90 \%$ lignin extraction, the monomer yields were similar between all poplar samples at approximately $32 \mathrm{wt} \%$. HSQC-NMR spectroscopy, GPC, and silylated GC-MS were performed to understand differences in the high molecular weight fractions of each extracted lignin oil. GPC showed an increase in molecular weight of lignin oil extracted at later times on stream in the flow-through extraction. NMR spectroscopy indicated that these large molecular weight fragments consisted of primarily $S$ lignin units. Analysis of the dimers produced at different times on stream showed an increase in $S-G \beta-5$ linkages over time as well as a high amount of S-S $\beta-\beta$ linkages throughout the extraction. The similar monomer yields between a wide range of naturally variant wood samples is likely caused by the plants ability to regulate lignification.

\footnotetext{
Methods

Catalyst synthesis. Nickel on carbon $(\mathrm{Ni} / \mathrm{C})$ catalysts were synthesized following our previously published wet impregnation procedure ${ }^{46}$. Briefly, to prepare $10 \mathrm{~g}$ of $15 \mathrm{wt} \%$ catalyst, $7.432 \mathrm{~g}$ nickel nitrate hexahydrate (Sigma-Aldrich) was dissolved in $10.2 \mathrm{~mL}$ deionized water and added to $8.5 \mathrm{~g}$ Darco carbon (Sigma-Aldrich, $100 \mathrm{mesh}$ ). After equilibrating at ambient conditions for $16 \mathrm{~h}$ and drying for $24 \mathrm{~h}$ at $120^{\circ} \mathrm{C}$, the catalyst was thermally reduced in a tube furnace by heating to $450^{\circ} \mathrm{C}$ over $1 \mathrm{~h}$ and then holding for $2 \mathrm{~h}$ at $450^{\circ} \mathrm{C}$ under flowing nitrogen $\left(100 \mathrm{~mL} \mathrm{~min}^{-1}\right)$. The catalyst was used in batch reactions without further treatment. For flow reactions, the catalyst required pelletizing to ensure a good flow profile and prevent large pressure drops. Since carbon does not pelletize easily, the $15 \mathrm{wt} \% \mathrm{Ni} / \mathrm{C}$ was mixed
}

50/50 w/w with $\mathrm{SiO}_{2}$ (Sigma-Aldrich, $12 \mathrm{~nm}$ ) by agitating with a stir bar for $24 \mathrm{~h}$ The resulting physical mixture was pelletized using 6 tons of pressure and sieved to $100-200$ mesh.

Ruthenium on carbon $(\mathrm{Ru} / \mathrm{C})$ was purchased from Sigma-Aldrich $(5 \mathrm{wt} \%$ loading) and used as-received.

Compositional analysis of biomass. Compositional analysis of poplar was performed based on NREL's Laboratory Analytical Procedure (LAP) at 1/6 the scale $^{64,65}$. To dissolve cellulose and hemicellulose, extracted poplar $(0.05 \mathrm{~g})$ was treated with $72 \mathrm{wt} \%$ sulfuric acid $(0.5 \mathrm{~mL})$ for $1 \mathrm{~h}$ at $30^{\circ} \mathrm{C}$. Water was added to decrease the slurry concentration to $4 \mathrm{wt} \%$. The slurry was then heated to $121^{\circ} \mathrm{C}$ for $1 \mathrm{~h}$ in an autoclave and filtered to yield an acid insoluble lignin-rich fraction. This insoluble fraction was oxidized in air at $575^{\circ} \mathrm{C}$ for at least $4 \mathrm{~h}$ to determine the ash content. UV/Vis spectroscopy (Thermo Scientific Nanodrop 8000 spectrophotometer) was used to determine acid-soluble lignin content, using absorbance measurements at $240 \mathrm{~nm}$ with an extinction coefficient of 2.5. High-performance liquid chromatography (HPLC, Agilent $1100 \mathrm{HPLC}$ ) with a refractive index detector at $55^{\circ} \mathrm{C}$ and a Shodex Sugar SP0810 column at $85^{\circ} \mathrm{C}$

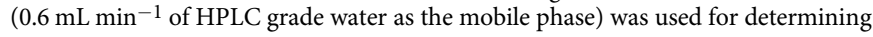
sugar content.

Thioacidolysis was performed in duplicate on $2 \mathrm{mg}$ of ground sample, as reported in Harman-Ware et al. ${ }^{48}$.

Biomass reactivity studies. Batch reactions were performed using a mechanically stirred reactor (Parr, 4560 series, $100 \mathrm{~mL}$ ) equipped with an overhead stirrer. The reactor was loaded with milled poplar $(0.96-1.15 \mathrm{~g}, 0.075<d<0.25 \mathrm{~mm})$, catalyst $(0.15 \mathrm{~g})$, and methanol $(50 \mathrm{~mL})$, then pressurized to $3 \mathrm{MPa}$ with hydrogen gas. While stirring at 700 r.p.m., the reactor was heated to $250^{\circ} \mathrm{C}$ over $1 \mathrm{~h}$, held at temperature for $3 \mathrm{~h}$, and quenched with an ice bath. After reaction, the lignin oil fraction was isolated by filtering solids with a $0.2 \mu \mathrm{m}$ filter, removing methanol under vacuum and performing a dichloromethane (DCM)/water extraction to remove water-soluble sugars. The $\mathrm{DCM} /$ water extraction involved dissolving the oil in $20 \mathrm{~mL} 1: 1 \mathrm{v} / \mathrm{v}$ DCM and water, recovering the DCM phase, and extracting the water with two additional DCM rinses. Dichloromethane was then removed under vacuum to recover the lignin oil that was then used for product quantification.

Flow-through RCF was performed in a flow-through dual-bed reactor,

following our previously published procedure (which also provides in-depth details of the reactor construction $)^{46}$. Briefly, the upstream $1 / 2^{\prime \prime}$ OD stainless steel solvolysis reactor was packed with $1 \mathrm{~g}$ of poplar wood $(0.96-1.15 \mathrm{~g}, 0.075<d<$ $0.25 \mathrm{~mm}$ ), held in place with two glass wool plugs, with the remaining void volume filled with $1 \mathrm{~mm}$ glass beads. The downstream $1 / 4^{\prime \prime}$ OD reduction reactor was packed with $0.3 \mathrm{~g} 15 \% \mathrm{Ni} / \mathrm{C}\left(50 / 50 \mathrm{SiO}_{2}\right.$, pelletized to $100-200$ mesh), also held in place with glass wool plugs, with the remaining void volume filled with glass beads. 
Methanol was flowed at $0.5 \mathrm{~mL} \mathrm{~min}-1$ into the bottom solvolysis reactor; the solvolysis effluent was mixed with hydrogen $(50 \mathrm{~mL} \mathrm{~min}-1$ STP) before flowing through the reduction reactor. The reactor was maintained at 60 bar to ensure the methanol remained a liquid at the operating temperature of $190^{\circ} \mathrm{C}$. Reaction samples were taken every $10 \mathrm{~min}$ and analyzed by GC-FID. Liquid oil yields were determined from binned samples which were extracted with $\mathrm{DCM} /$ water $(3 \times 10 \mathrm{~mL})$

Lignin monomer quantification. Samples were quantified using gas chromatography (Model $7890 \mathrm{~A}$, Agilent). A $1 \mu \mathrm{L}$ injection volume was used through a 30 $\mathrm{m} \times 250 \mu \mathrm{m} \times 0.25 \mu \mathrm{m}$ column (DB-1701, Agilent) with a split ratio of 10:1. An inlet temperature of $280^{\circ} \mathrm{C}$ and an oven temperature of $50^{\circ} \mathrm{C}$ with a $10^{\circ} \mathrm{C} \mathrm{min}-1$ ramp to $280^{\circ} \mathrm{C}$ was used with an overall run time of $29 \mathrm{~min}$. An FID was used to quantify the products, with dimethoxybenzene as an external standard. Allyl syringol (Alfa Aesar, 98\%) and propyl guaiacol (Sigma-Aldrich, 99\%) were used as calibration standards Additionally, methyl paraben was not quantified in the monomer yield (although it was detected in every sample) as it is a pendent group to lignin attached by an ester linkage.

Derivatization and GC-MS procedure. Dried lignin oil samples (after DCM extraction) were prepared for derivatization by dissolving in dichloromethane to make a $10 \mathrm{mg} \mathrm{mL}^{-1}$ solution. Six hundred microliters of $10 \mathrm{mg} \mathrm{mL}^{-1}$ lignin oil solution was added to a $2 \mathrm{~mL}$ GC vial followed by $50 \mu \mathrm{L}$ of pyridine and $100 \mu \mathrm{L}$ of silylating agent. $\mathrm{N}, \mathrm{O}$-Bis(trimethylsilyl)trifluoroacetamide (BSTFA) with $1 \%$ trimethylchlorosilane (Sigma-Aldrich) was used as the silylating agent. Because it reacts readily with water, the BSTFA was ordered in $1 \mathrm{~mL}$ ampules and used immediately after opening, being sure to cap the GC-vials immediately after addition of BSTFA. The lignin oil, pyridine, and BSTFA solution was then heated for $20 \mathrm{~min}$ at $50^{\circ} \mathrm{C}$ before being injected on the GC-MS.

One microliter samples were manually injected with a split ratio of 10:1 and a split flow of $12 \mathrm{~mL} \mathrm{~min}^{-1}$. The inlet temperature was set to $280^{\circ} \mathrm{C}$. The oven was programmed to ramp from 150 to $300^{\circ} \mathrm{C}$ at a rate of $5{ }^{\circ} \mathrm{C} \mathrm{min}^{-1}$ and held at $300{ }^{\circ} \mathrm{C}$ for $18 \mathrm{~min}$ for a total run time of $49 \mathrm{~min}$. The Agilent Technologies 7820A GC System was equipped with an HP-5ms Ultra Inert $30 \mathrm{~m} \times 250 \mu \mathrm{m} \times 0.25 \mu \mathrm{m}$ column. Products were analyzed using an Agilent 5977B single quadrupole MS detector. A solvent delay of $15 \mathrm{~min}$ was used to prevent overloading the detector with the monomers.

GC-MS spectra were analyzed by comparing with dimer structures published in literature and by predicting structures that may be present and comparing them with unknown MS spectra.

GPC procedure. Oil samples were prepared for GPC by drying $200 \mu \mathrm{L}$ of $10 \mathrm{mg}$ $\mathrm{mL}^{-1}$ lignin oil in DCM solution (which was prepared for derivatization) to isolate $2 \mathrm{mg}$ of lignin oil in a GC vial. This was dissolved in $1 \mathrm{~mL}$ of THF to achieve a 2 $\mathrm{mg} \mathrm{mL} \mathrm{mL}^{-1}$ lignin oil in THF solution.

Three $5 \mu \mathrm{m}$ PLgel Agilent GPC columns were used in series arranged from larger pore size to smaller pore size from $10^{4}$ to $10^{3}$ to $50 \AA$. THF was used as the carrier solvent at a flow rate of $1 \mathrm{~mL} \mathrm{~min}^{-1}$. A Hewlett Packard 1100 series autosampler injected $20 \mu \mathrm{L}$ injection volumes. The columns were maintained at a constant temperature of $26^{\circ} \mathrm{C}$. The system ran at a pressure of approximately 100 bar, but this was not controlled and was a function of the flow rate and temperature. The eluents were analyzed using a UV diode array detector at a wavelength of $220 \mathrm{~nm}$ with a reference wavelength of $360 \mathrm{~nm}$ and a $4 \mathrm{~nm}$ slit.

A calibration for molecular weight vs residence time was created using a SigmaAldrich Fluka analytical polystyrene (low molecular) standard ReadyCal set M(p) $250-70000$. The molecular weight vs residence time curve was fit using a polynomial fit, which was used to convert all of the UV response vs residence time data into UV response vs molecular weight data.

HSQC-2D-NMR procedure. HSQC NMR spectra for extracted lignin oil samples (20 mg dissolved in $0.5 \mathrm{~mL}$ deuterated chloroform) were recorded at $25^{\circ} \mathrm{C}$ on a Bruker $400 \mathrm{MHz}$ nuclear magnetic resonance (NMR) spectrometer with a $5 \mathrm{~mm}$ $\mathrm{BBO}$ probe with a $\mathrm{Z}$ gradient. The hsqcetgpsi2 pulse program was used for HSQC. Spectra were acquired with a sweep width of $280 \mathrm{ppm}$ in the F1 $\left({ }^{13} \mathrm{C}\right)$ dimension and $18 \mathrm{ppm}$ in the F2 $\left({ }^{1} \mathrm{H}\right)$ dimension. A total of 300 scans were performed over 256 increments in the ${ }^{13} \mathrm{C}$ dimension with 1024 data points in the ${ }^{1} \mathrm{H}$ dimension. An acquisition time of $9.0 \mathrm{~ms}$ was used for ${ }^{13} \mathrm{C}$ and $71.2 \mathrm{~ms}$ was used for ${ }^{1} \mathrm{H}$. A relaxation delay of $1.5 \mathrm{~s}$ was used for each spectrum. The solvent peak of chloroform was used as an internal reference $(\delta \mathrm{H} 7.24, \delta \mathrm{C} 77.23 \mathrm{ppm})$.

\section{Data Availability}

The source data underlying all main text and supplemental figures are provided as a Source Data File.

Received: 14 November 2018 Accepted: 9 April 2019

Published online: 02 May 2019

\section{References}

1. Ragauskas, A. J. et al. The path forward for biofuels and biomaterials. Science 311, 484-489 (2006).

2. Ragauskas, A. J. et al. Lignin valorization: improving lignin processing in the biorefinery. Science 344, 1246843 (2014).

3. Rinaldi, R. et al. Paving the way for lignin valorisation: recent advances in bioengineering, biorefining and catalysis. Angew. Chem. Int. Ed. 55, 8164-8215 (2016).

4. Himmel, M. E. et al. Biomass recalcitrance: engineering plants and enzymes for biofuels production. Science 315, 804-807 (2007).

5. Sun, Z., Fridrich, Bl, de Santi, A., Elangovan, S. \& Barta, K. Bright side of lignin depolymerization: toward new platform chemicals. Chem. Rev. 118, 614-678 (2018).

6. Schutyser, W. et al. Chemicals from lignin: an interplay of lignocellulose fractionation, depolymerisation, and upgrading. Chem. Soc. Rev. 47, 852-908 (2018).

7. Vanholme, R., Demedts, B., Morreel, K., Ralph, J. \& Boerjan, W. Lignin biosynthesis and structure. Plant Physiol. 153, 895-905 (2010).

8. Davin, L. B. et al. Dissection of lignin macromolecular configuration and assembly: comparison to related biochemical processes in allyl/propenyl phenol and lignan biosynthesis. Nat. Prod. Rep. 25, 1015-1090 (2008).

9. Boerjan, W., Ralph, J. \& Baucher, M. Lignin biosynthesis. Annu. Rev. Plant Biol. 54, 519-546 (2003).

10. Anderson, E., Crisci, A., Murugappan, K. \& Román-Leshkov, Y. Bifunctional molybdenum polyoxometalates for the combined hydrodeoxygenation and alkylation of lignin-derived model phenolics. ChemSusChem 10, 2226-2234 (2017).

11. Verboekend, D., Liao, Y., Schutyser, W. \& Sels, B. F. Alkylphenols to phenol and olefins by zeolite catalysis: a pathway to valorize raw and fossilized lignocellulose. Green Chem. 18, 297-306 (2016).

12. Schutyser, W. et al. Selective conversion of lignin-derivable 4-alkylguaiacols to 4-alkylcyclohexanols over noble and non-noble-metal catalysts. ACS Sustain. Chem. Eng. 4, 5336-5346 (2016).

13. Cao, Z., Dierks, M., Clough, M. T., de Castro, I. B. D. \& Rinaldi, R. A convergent approach for a deep converting lignin-first biorefinery rendering high-energy-density drop-in fuels. Joule 2, 1118-1133 (2018).

14. Johnson, C. W. \& Beckham, G. T. Aromatic catabolic pathway selection for optimal production of pyruvate and lactate from lignin. Metab. Eng. 28, 240-247 (2015).

15. Sun, Z. et al. Complete lignocellulose conversion with integrated catalyst recycling yielding valuable aromatics and fuels. Nat. Catal. 1, 82 (2018).

16. Wang, H., Pu, Y., Ragauskas, A. \& Yang, B. From lignin to valuable products -strategies, challenges, and prospects. Bioresour. Technol. 271, 449-461 (2018).

17. Wang, L. et al. Mesoporous ZSM-5 zeolite-supported Ru nanoparticles as highly efficient catalysts for upgrading phenolic biomolecules. ACS Catal. 5, 2727-2734 (2015)

18. Liao, Y. et al. Propylphenol to phenol and propylene over acidic zeolites: role of shape selectivity and presence of steam. ACS Catal. 8, 7861-7878 (2018).

19. Yoshikawa, T., Umezawa, T., Nakasaka, Y. \& Masuda, T. Conversion of alkylphenol to phenol via transalkylation using zeolite catalysts. Catal Today (2018). https://doi.org/10.1016/j.cattod.2018.08.009.

20. Zhang, J., Lombardo, L., Gözaydın, G., Dyson, P. J. \& Yan, N. Single-step conversion of lignin monomers to phenol: bridging the gap between lignin and high-value chemicals. Chin. J. Catal. 39, 1445-1452 (2018).

21. Wang, S., Shuai, L., Saha, B., Vlachos, D. G. \& Epps, T. H. From tree to tape direct synthesis of pressure sensitive adhesives from depolymerized raw lignocellulosic biomass. ACS Cent. Sci. 4, 701-708 (2018).

22. Zhao, S. \& Abu-Omar, M. M. Biobased epoxy nanocomposites derived from lignin-based monomers. Biomacromolecules 16, 2025-2031 (2015).

23. Zhao, S. \& Abu-Omar, M. M. Synthesis of renewable thermoset polymers through successive lignin modification using lignin-derived phenols. ACS Sustain. Chem. Eng. 5, 5059-5066 (2017).

24. Vardon, D. R. et al. Adipic acid production from lignin. Energy Environ. Sci. 8, 617-628 (2015).

25. Johnson, C. W. et al. Enhancing muconic acid production from glucose and lignin-derived aromatic compounds via increased protocatechuate decarboxylase activity. Metab. Eng. Commun. 3, 111-119 (2016).

26. Van den Bosch, S. et al. Reductive lignocellulose fractionation into soluble lignin-derived phenolic monomers and dimers and processable carbohydrate pulps. Energy Environ. Sci. 8, 1748-1763 (2015).

27. Stewart, J. J., Akiyama, T., Chapple, C., Ralph, J. \& Mansfield, S. D. The effects on lignin structure of overexpression of ferulate 5-hydroxylase in hybrid poplar1. Plant Physiol. 150, 621-635 (2009).

28. Shuai, L. et al. Formaldehyde stabilization facilitates lignin monomer production during biomass depolymerization. Science 354, 329-333 (2016). 
29. Parsell, T. et al. A synergistic biorefinery based on catalytic conversion of lignin prior to cellulose starting from lignocellulosic biomass. Green Chem. 17, 1492-1499 (2015).

30. Luo, H. \& Abu-Omar, M. M. Lignin extraction and catalytic upgrading from genetically modified poplar. Green Chem. 20, 745-753 (2018).

31. Renders, T., Van den Bosch, S., Koelewijn, S.-F., Schutyser, W. \& Sels, B. Lignin-first biomass fractionation: the advent of active stabilisation strategies. Energy Environ. Sci. 10, 1551-1557 (2017).

32. Zakzeski, J., Bruijnincx, P. C., Jongerius, A. L. \& Weckhuysen, B. M. The catalytic valorization of lignin for the production of renewable chemicals. Chem. Rev. 110, 3552-3599 (2010).

33. Anderson, E. M., Stone, M. L., Hülsey, M. J., Beckham, G. T. \& RomanLeshkov, Y. Kinetic studies of lignin solvolysis and reduction by reductive catalytic fractionation decoupled in flow-through reactors. ACS Sustain. Chem. Eng. 6, 7951-7959 (2018).

34. Renders, T. et al. Synergetic effects of alcohol/water mixing on the catalytic reductive fractionation of poplar wood. ACS Sustain. Chem. Eng. 4, 6894-6904 (2016).

35. Schutyser, W. et al. Influence of bio-based solvents on the catalytic reductive fractionation of birch wood. Green Chem. 17, 5035-5045 (2015).

36. Ferrini, P. \& Rinaldi, R. Catalytic biorefining of plant biomass to non-pyrolytic lignin bio-oil and carbohydrates through hydrogen transfer reactions. Angew. Chem. Int. Ed. 53, 8634-8639 (2014).

37. Paola, F. A., R, C. \& Roberto, R. Catalytic upstream biorefining through hydrogen transfer reactions: understanding the process from the pulp perspective. ChemSusChem 9, 3171-3180 (2016).

38. Chesi, C., de Castro, I. B. D., Clough, M. T., Ferrini, P. \& Rinaldi, R. The influence of hemicellulose sugars on product distribution of early-stage conversion of lignin oligomers catalysed by Raney nickel. ChemCatChem $\mathbf{8}$, 2079-2088 (2016).

39. Parsell, T. H. et al. Cleavage and hydrodeoxygenation (HDO) of C-O bonds relevant to lignin conversion using $\mathrm{Pd} / \mathrm{Zn}$ synergistic catalysis. Chem. Sci. 4, 806-813 (2013).

40. Anderson, E. M. et al. Reductive catalytic fractionation of corn stover lignin. ACS Sustain. Chem. Eng. 4, 6940-6950 (2016).

41. Song, Q. et al. Lignin depolymerization (LDP) in alcohol over nickel-based catalysts via a fragmentation-hydrogenolysis process. Energy Environ. Sci. 6, 994-1007 (2013).

42. Chesi, C., de Castro, I. B., Clough, M. T., Ferrini, P. \& Rinaldi, R. The influence of hemicellulose sugars on product distribution of early-stage conversion of lignin oligomers catalysed by Raney nickel. ChemCatChem $\mathbf{8}$, 2079-2088 (2016).

43. Stone, M. L. et al. Reductive catalytic fractionation of C-lignin. ACS Sustain. Chem. Eng. 6, 11211-11218 (2018).

44. Muchero, W. et al. High-resolution genetic mapping of allelic variants associated with cell wall chemistry in Populus. BMC Genomics 16, 24 (2015).

45. Studer, M. H. et al. Lignin content in natural Populus variants affects sugar release. Proc. Natl Acad. Sci. USA 108, 6300-6305 (2011).

46. Anderson, E. M. et al. Flowthrough reductive catalytic fractionation of biomass. Joule 1, 613-622 (2017).

47. Yue, F., Lu, F., Regner, M., Sun, R. \& Ralph, J. Lignin-derived thioacidolysis dimers: reevaluation, new products, authentication, and quantification. ChemSusChem 10, 830-835 (2017).

48. Harman-Ware, A. E. et al. A thioacidolysis method tailored for higherthroughput quantitative analysis of lignin monomers. Biotechnol. J. 11, 1268-1273 (2016).

49. Lapierre, C., Monties, B. \& Rolando, C. Thioacidolysis of poplar lignins: identification of monomeric syringyl products and characterization of guaiacyl-syringyl lignin fractions. Holzforschung 40, 113-118 (1986).

50. Mansfield, S. D., Kim, H., Lu, F. \& Ralph, J. Whole plant cell wall characterization using solution-state 2D NMR. Nat. Protoc. 7, 1579 (2012).

51. Kim, H., Ralph, J. \& Akiyama, T. Solution-state 2D NMR of ball-milled plant cell wall gels in DMSO-d 6. Bioenergy Res. 1, 56-66 (2008).

52. Heitner, C., Dimmel, D. \& Schmidt, J. Lignin and Lignans: Advances in Chemistry (CRC Press, Boca Raton, FL, 2016).

53. Lu, F. \& Ralph, J. Novel tetrahydrofuran structures derived from $\beta$ - $\beta$-coupling reactions involving sinapyl acetate in Kenaf lignins. Org. Biomol. Chem. 6, 3681-3694 (2008).

54. Lancefield, C. S., Panovic, I., Deuss, P. J., Barta, K. \& Westwood, N. J. Pre-treatment of lignocellulosic feedstocks using biorenewable alcohols: towards complete biomass valorisation. Green Chem. 19, 202-214 (2017).

55. Galkin, M. V. \& Samec, J. S. M. Lignin valorization through catalytic lignocellulose fractionation: a fundamental platform for the future biorefinery. ChemSusChem 9, 1544-1558 (2016).

56. Liu, C.-J. Deciphering the enigma of lignification: precursor transport, oxidation, and the topochemistry of lignin assembly. Mol. Plant 5, 304-317 (2012).
57. Tanahashi, M., Takeuchi, H. \& Higuchi, T. Dehydrogenative polymerization of 3, 5-disubstituted p-coumaryl alcohols. Wood Res. 61 , 44-53 (1976)

58. Syrjänen, K. \& Brunow, G. Regioselectivity in lignin biosynthesis. The influence of dimerization and cross-coupling. J. Chem. Soc. Perkin Trans. 1, 183-187 (2000).

59. Tanahashi, M., Aoki, T. \& Higuchi, T. Dehydrogenative polymerization of monolignols by peroxidase and $\mathrm{H} 2 \mathrm{O} 2$ in a dialysis tube. II: Estimation of molecular weights by thermal softening method. Holzforschung 36, 117-122 (1982).

60. Saake, B., Argyropoulos, D. S., Beinhoff, O. \& Faix, O. A comparison of lignin polymer models (DHPs) and lignins by 31P NMR spectroscopy. Phytochemistry 43, 499-507 (1996).

61. van Parijs, F. R. D., Morreel, K., Ralph, J., Boerjan, W. \& Merks, R. M. H Modeling lignin polymerization. I. Simulation model of dehydrogenation polymers. Plant Physiol. 153, 1332-1344 (2010).

62. Gani, T. Z. et al. Quantum mechanical calculations suggest that lignin polymerization is kinetically controlled. Preprint at https://doi.org/10.26434/ chemrxiv.7334564 (2019).

63. Li, M., Pu, Y. \& Ragauskas, A. J. Current understanding of the correlation of lignin structure with biomass recalcitrance. Front. Chem. 4, 45 (2016).

64. Sluiter, A., Ruiz, R., Sluiter J. \& Templeton, D. Determination of Extractives in Biomass. Technical Report NREL, 1617, (2005).

65. Sluiter, A., Hames, B., Ruiz, R., Scarlata, C., Sluiter, J., Templeton, D., \& Crocker, D. Determination of Structural Carbohydrates and Lignin in Biomass. Technical Report NREL (2008).

\section{Acknowledgements}

Funding for E.M.A., M.L.S., W.M., G.T.B., and Y.R.-L. was provided by The Center for Bioenergy Innovation a U.S. Department of Energy Research Center supported by the Office of Biological and Environmental Research in the DOE Office of Science. Additionally, R.K., M.R., K.R., and G.T.B. thank the US Department of Energy Bioenergy Technologies Office for funding under Contract DE-AC36-08GO28308 with the National Renewable Energy Laboratory.

\section{Author contributions}

E.M.A., M.L.S., G.T.B., and Y.R.-L. conceived the research ideas and designed the experiments. E.M.A and M.L.S performed RCF experiments and data analysis. R.K. performed HSQC-NMR. M.R. performed compositional analysis. W.M. supplied and characterized natural variant samples. K.R. performed thioacidolysis. E.M.A., M.L.S., G.T.B., and Y.R.-L. co-wrote the paper. Y.R.-L. supervised the project.

\section{Additional information}

Supplementary Information accompanies this paper at https://doi.org/10.1038/s41467019-09986-1.

Competing interests: The authors declare no competing interests.

Reprints and permission information is available online at http://npg.nature.com/ reprintsandpermissions/

Journal peer review information: Nature Communications thanks the anonymous reviewers for their contribution to the peer review of this work. Peer reviewer reports are available.

Publisher's note: Springer Nature remains neutral with regard to jurisdictional claims in published maps and institutional affiliations.

Open Access This article is licensed under a Creative Commons Attribution 4.0 International License, which permits use, sharing, adaptation, distribution and reproduction in any medium or format, as long as you give appropriate credit to the original author(s) and the source, provide a link to the Creative Commons license, and indicate if changes were made. The images or other third party material in this article are included in the article's Creative Commons license, unless indicated otherwise in a credit line to the material. If material is not included in the article's Creative Commons license and your intended use is not permitted by statutory regulation or exceeds the permitted use, you will need to obtain permission directly from the copyright holder. To view a copy of this license, visit http://creativecommons.org/ licenses/by/4.0/

(C) The Author(s) 2019 